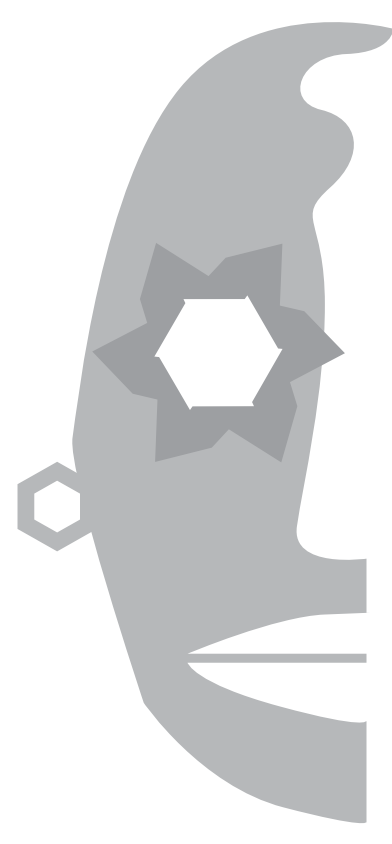

Karen Poe Lang

Universidad

de Costa Rica (UCR)

\section{Más allá de la identidad de género: sexualidad y transgresión en Sopa de caracol de Arturo Arias}

\section{Resumen}

En este ensayo se propone una lectura de la novela Sopa de caracol (2002) del escritor guatemalteco Arturo Arias, centrada en el tema de la función de la sexualidad como elemento desubjetivante del protagonista. Se examina también cómo la estética del grotesco y el modelo carnavalesco son puestos en movimiento para desestabilizar la identidad de género y así mostrar la imposibilidad de reconstruirse después de la catástrofe de la guerra.

Palabras clave: novela centroamericana; posguerra; identidad de género; sexualidad; desubjetivación.

\begin{abstract}
In this essay we propose an interpretation of the novel Sopa de caracol (2002) by Guatemalan writer Arturo Arias based on the role of sexuality in the desubjetivization of the protagonist. We also analyze how the aesthetic of the grotesque and the carnivalesque model are set in motion to destabilize gender identity and thus demonstrate its inability to reconstruct itself after the catastrophe of war.
\end{abstract}

Keywords: Central American novel; post-war; gender identity; sexuality; desubjectivization. 


\section{Introducción}

En la introducción a un reciente volumen colectivo sobre la narrativa de Arturo Arias, Myron Ávila (2014: xvii) propone que se trata de "uno de los novelistas guatemaltecos más innovadores e importantes de nuestro momento". Con la intención de contribuir al estudio de la obra de este autor, fundamental en las letras centroamericanas, este ensayo analiza el papel desestabilizador de la sexualidad en Sopa de Caracol (2002), novela que presenta una forma particular de encarar el desencanto y la impotencia ante el fracaso del proceso revolucionario ocurrido a fines del siglo XX en Guatemala. Publicada a principios del siglo XXI, el texto muestra cómo, tras la firma de los Acuerdos de Paz (que no resolvieron los problemas de desigualdad y pobreza en Guatemala), los distintos sectores de la izquierda quedaron desarticulados, sin un proyecto utópico que pudiese dar sentido a las vidas de muchas personas que creyeron en la posibilidad de trasformar radicalmente la sociedad mediante la revolución armada.

A partir de estrategias narrativas asociadas al modo carnavalesco ${ }^{1}$, el texto, cuyo personaje principal es un exmilitante de izquierda, muestra la imposibilidad de recontruir(se) después de la catástrofe de la guerra. Arias recurre a la estética del grotesco para representar la abjección de un personaje inhumanamente lúcido, capaz de evaluar sus actos descarnadamente y así revelar su historia de militante en una organización clandestina. La sexualidad aparece como el espacio carnavalesco en el cual se rompe la socialidad y se quiebran los tabués que rigen inconscientemente la vida social. La novela propone un recorrido, vehiculizado por una sexualidad fuera de lo socialmente permitido, hacia la desubjetivación del personaje principal, quien en el último capítulo declara: "Me dejo llevar suavemente [...] te admito que estoy sorprendido y conmovido por la pérdida de los más elementales indicadores de identidad. Yo no sé quién soy”. (Arias 2002: 276)

Este proceso de despersonalización y de pérdida de sí, a través de la sexualidad, permite trascender uno de los pilares de la división normativizante de la estructura social: la identidad de género. Al igual que muchas otras novelas centroamericanas del periodo, desde el título se propone al lector una relación de intertextualidad con el acervo musical centroamericano y del Caribe. Sopa de caracol ${ }^{2}$ (plato beliceño y nombre de una canción) es un verdadero leitmotiv en la novela de Arias.

1 En Taylor Kane, A. (2014). El juego y la ideología en Sopa de caracol en Con mi país bajo el brazo. Compendio crítico sobre la narrativa de Arturo Arias, Ávila, M. A. (comp), Guatemala: F\&G, pp. 125146 puede leerse un interesante análisis de Sopa de caracol a partir de la teoría bajtiniana del carnaval, centrada sobre todo en el aspecto lúdico. La lectura que planteo a continuación, a pesar de trabajar el tema del carnaval, privilegia otros aspectos.

2 Sopa de caracol es el nombre de una canción del escritor garínagu beliceño Hernán "Chico" Ramos que incluye elementos de la música garífuna y punta. En 1991 fue en éxito comercial gracias a una versión de la agrupación hondureña Banda Blanca. 


\section{La insoportable tristeza del carnaval}

Sopa de caracol está construida como un texto carnavalesco, su tiempo transcurre durante un banquete que da inicio con la presentación del menú, y sus capítulos siguen el orden establecido por los platillos ofrecidos a los comensales. El relato avanza conforme se sirven y degluten los manjares y licores, producto del sincretismo culinario de Centroamérica y Europa. Se trata de una novela polifónica de una enorme riqueza intertextual (como todas aquellas que acogen en su seno la cosmogonía carnavalesca) en la cual se dan la mano el lenguaje de la calle, los modismos del castellano en Centroamerica, el portugués y el inglés criollo de Belice, nuestra música popular y algunos textos considerados "clásicos", entre otros. Julia Kristeva, en su lectura de Bajtin, señala que "sobre la escena generalizada del carnaval, el lenguaje se parodia y se relativiza, repudiando su papel de representación (lo que provoca risa), sin llegar por ello a librarse de él. [...] Viciosa (quiero decir: ambivalente), a la vez representativa y antirepresentativa, la estructura carnavalesca es anti-ideológica, anticristiana y antirracionalista". (Kristeva, 1997: 15)

Ya desde el inicio de la novela, en el capítulo titulado "Introducción al menú", el texto de Arias es un juego permanente con las estructuras representativas del lenguaje, un intento sistemático de quebrar la lógica y el sentido (¿único?) para dar paso al enloquecimiento festivo de los signos. Uno de sus rasgos más evidentes es esa "indestructible vitalidad lingüística" que Bajtín (1998: 32) asocia con la cosmovisión carnavalesca:

Ya afirmaba el poeta que bailar es encontrar la unidad que forman los vivientes y los muertos. También sé que las partes son algo más que el laberinto de la oreja. La explicación más simple del círculo hermenéutico es que para entender una solitaria parte hay que ilusionarse con la creencia de comprender el todo. Para agarrar ese elusivo toldo carente de verdades absolutas, de conocimientos objetivos, de significados estables, toldo disfrazado de todo y no de toro, hay que captar las pletóricas partes platónicamente preñadas de significantes pedantemente putones. El todo, el toldo, puede ser un menú. (Arias, 2002: 9)

Este fragmento muestra una característica de toda la novela, a saber, que las palabras muchas veces están ordenadas según su aspecto sonoro, produciendo sentidos sorprendentes. El significante prevalece sobre el significado para interrumpir el orden lógico y esperado por el lector. La pulsión quiebra el logos (entendido en su triple acepción de razón, ley y lenguaje). Este manejo festivo de la lengua establece un contrapunto con la violenta tristeza de los hechos narrados. Como ha indicado Kristeva: "[...] el carnaval cuestiona a Dios, autoridad y ley social; es revolucionario en la medida en que es dialógico: no es asombroso que a causa de 
ese discurso subversivo el término de 'carnaval' haya tomado en nuestra sociedad una significación peyorativa y únicamente caricaturesca.” (1997: 14)

Si bien es cierto que, debido a la traducción de la obra de Bajtin al francés, al inglés y al castellano, el carnaval (convertido en teoría), hoy en día es una moda, no ha sucedido lo mismo con las implicaciones de esta cosmovisión en la escritura, cuyos excesos no siempre se perdonan. Habría que tomar en cuenta este aspecto de la novela de Arias en los avatares de su recepción. Aunque no es el tema de este trabajo, cierto silencio del discurso crítico sobre esta novela podría tener su raíz en ese carácter subversivo e incluso antisocial del texto y en su lógica, en cierto modo, sadiana. Además, no se debe olvidar que la obra de Sade y la de Arias comparten un hecho en común: son producciones realizadas en un periodo convulso (revolucionario o postrevolucionario) que enfrentan la intimidad salvaje del ser desde una ética del placer que se contrapone a una ética del bien. Es posible oponer al discurso monológico de la épica - basado en una ética del bienel discurso dialógico del carnaval, fundamentado en una ética del placer.

En este sentido debe ser leído el potencial transgresor del texto de Arias, no solamente en su literalidad sino en su dimensión de ruptura de las normas sociales que nuestra época impone sobre nuestros cuerpos. Quizá lo que desestabiliza al lector en la novela de Arias es el despliegue de un pensamiento que se atreve a ir más allá de las verdades establecidas para representar el infierno de la interioridad.

Bajtín ${ }^{3}$ hace una apreciación respecto de la cultura cómica popular de la Edad Media que puede iluminar, leída al revés, la concepción del carnaval en los textos modernos:

Por eso aún no se ha descubierto la esencia de estos fenómenos, que fueron estudiados únicamente desde el punto de vista de las reglas culturales, estéticas y literarias de la época moderna, sin ubicarlos en la época a la que pertenecen. Fueron por el contrario modernizados, lo que explica por qué fueron interpretados. (Bajtín, 1998: 23)

Este error, señalado por el teórico ruso, ocurre frecuentemente en las lecturas de lo carnavalesco que se imponen a los textos contamporáneos, al interpretarlos como si respondieran a la lógica del carnaval medieval. Es imposible no tomar nota de algunos hechos decisivos que imposibilitan dicha concepción. Por una parte, el tejido social y la colectividad no tienen hoy el mismo lugar ni la misma función que en la Edad Media; ni su contraparte, el individuo, es tampoco ni mínimamente semejante. Pero fundamentalmente, si la cosmovisión carnavalesca atentaba, según Bajtín, contra la Iglesia y el Estado feudal, dos instituciones que hoy, o han dejado de existir, o se han modificado tanto que es imposible

3 Bajtín insiste en historizar el fenómeno carnavalesco y plantea que con el romanticismo y las vanguardias, la cosmogonía carnavalesca se degrada y pierde gran parte de su poder regenerativo. 
reconocerlas, una pregunta es inevitable: ¿Cuáles son las instituciones contra las que se opone la cosmovisión carnavalesca en nuestra época?

Si tomamos en cuenta las teorizaciones de Foucault ${ }^{4}$ (1990: 24) sobre el poder moderno como un proceso de normalización de la vida que hace de los sujetos sus propios guardianes, podría suponerse que el carnaval ejerce su poder de transformación y destrucción en el centro/descentrado de la subjetividad humana. Mi hipótesis es que la fuerza transgresora de la cosmovisión carnavalesca en nuestra época destruye las jerarquías y las leyes sociales, destruyendo su modo de operar en la individualidad. Es la interiorización de la norma y la constitución subjetiva lo que debe transformarse. Por eso, en la carnavalización moderna no basta con el disfraz y el cambio de rol (el tonto convertido en rey), sino que se golpea una institución poderosa: la identidad. En el caso del texto de Arias, la identidad sexual ${ }^{5}$.

\section{Una sexualidad a pura pérdida}

En Sopa de Caracol el potencial transgresor logra su punto más alto en dos escenas fundamentales: la relación del narrador con su perra y la orgía al final del texto. Lo que hace de estas escenas una propuesta transgresora no son las acciones concretas, sino la postura subjetiva desde la cual se realizan y la visión del narrador (más allá del bien y del mal) sobre las mismas.

Respecto de la primera escena, el narrador protagonista hace depender su relación con Amaranta (la perra Golden Retriever) de su soledad. Cabe destacar que el modo como es narrado el episodio constituye una parodia de la importancia que tienen los perros en los hogares estadounidenses. Existe toda una subcultura (expresada en hoteles y restaurantes finísimos para canes) para la cual es lógico e incuestionable que muchos perros vivan mejor que los niños hambrientos del tercer mundo. Por otra parte, Hollywood ha establecido la imagen estereotipada de la familia típica norteamericana, con dos niños y el infaltable perro. No es casual que el episodio con la perra tenga lugar en San Francisco y no en Guatemala, México o Río de Janeiro, que son los otros territorios en que se desarrolla el relato. Lo más subversivo de esta escena es que el personaje dice encontrar el amor verdadero en esa relación, algo que no ha conseguido en sus vínculos con mujeres. El texto pervierte el sentido de la concepción romántica del amor (que

4 Michel Foucault propone que: "Nos es preciso imaginar y construir lo que podríamos ser para desembarazarnos de esa especie de "doble coerción” política que es la individuación y la totalización de las estructuras del poder moderno”. (1990: 24) Además, no hay que olvidar que para Foucault el cuerpo y la sexualidad son espacios extremadamente densos y habitados por diversas instancias de poder.

5 Arias profundiza esta desestabilización de la identidad sexual en su última novela Arias de don Giovanni, publicada en 2010, al hacer de un(a) transexual el personaje protagónico. Para un análisis de este texto ver: Poe, K. (2014). Arias de don Giovanni. Hacia una poética del cuerpo transexual, en Con mi país bajo el brazo, Avila, M. A. (comp). Guatemala: F\&G, pp. 149-162 
ha marcado el arte y la cultura occidentales durante siglos) al presentar la posibilidad de que este amor ocurra entre un animal y una persona.

Quebramos el ambiente con nuestra propia música en la cual los ladridos y aullidos se anudaron pulverizando juntos las paredes en su ascenso hasta las maltratadas capas de ozono desde donde anunciaron un nuevo amanecer cultural para la armoniosa fusión entre animal y hombre.

Habría sido un matrimonio perfecto de no excedernos en el abuso de la pasión. (Arias 2002: 236-37)

Como todo amor romántico, su fin no se debe a su propio devenir, sino a la intervención de la sociedad. En este caso, por un descuido en la playa, Amaranta es apartada de su dueño y adoptada por una familia "bien" que no le hará "cochinadas'. El protagonista dice al respecto: "Fue así como perdí al que pudo ser el gran amor de mi vida". Otro aspecto subversivo del texto es su forma de presentar el bestialismo como algo natural y en un ambiente bucólico de respeto y amor entre los participantes. La mirada del narrador no victimiza al animal ni condena al hombre por su conducta:

Obviamente el acercamiento con Amaranta fue cada vez mayor. Ya no concebía la posibilidad de dormir sin ella pero no era lo único que ya no concebía. Como concebía muchas cosas decidí poquito a poco concebir más todavía porque de concebir se trataba aunque con ella no pudiera concebir cachorros y en la concepción se me iba la imaginación. Al fin, era una perra grande y pensé no sin razón que era capaz de mayores compromisos que a lo mejor respondían a las apasionadas esperanzas de ambos. [...] Empecé por explorar sus resquicios con la debida prudencia y recato, apenas tanteando o, si prefieren, tentando, para indagar los milagros de la elasticidad

[...] La tentación de hundirme en tan tentadora brea se me hacía irresistible y ya no solo con los dedos. La tumescencia atronadora exigía mayores empréstitos que redituaran ganancias líquidas. Amaranta ni se quejaba ni objetaba a tanta y tan súbita atención Pasó entonces que entré por la puerta grande con Amaranta y fue grandioso por su deleite. (Arias 2002: 235-36)

El bestialismo suele ser presentado, en los textos culturales y médicos de nuestra época, como una perversión sexual, cometida por seres infames o débiles mentales que no saben lo que hacen. Sopa de caracol, por el contrario, presenta una relación armoniosa y hasta deseable entre un hombre lúcido, inteligente y profesor universitario con su perra, que parece disfrutar enormemente de la situación. De ese modo queda planteado uno de los descubrimientos más desgarradores de la teoría psicoanalítica, a saber, la constatación freudiana de la labilidad pulsional, es decir, que la pulsión sexual no tiene objeto definido. Por esta razón, una 
de las tareas centrales de todas las culturas es encaminar esa energía sexual por vías socialmente aceptables, según las normas y leyes imperantes en determinado momento histórico. La novela de Arias marcha a contrapelo de esa empresa normalizadora. La otra escena que atenta abiertamente contra las reglas sociales es el último capítulo, titulado "Sopa de caracol", en el cual se lleva a cabo la orgía. La sopa de caracol cumple dos funciones importantes: como alimento afrodisíaco y como estímulo del baile.

Oigan el tiempo se paró. Estamos ya en el espacio de lo sagrado, en la mística unión con el cosmos que sólo puede conseguirse con la sopa de caracol. [...] Parecen coro griego hablando todas al mismo tiempo. Ni consigo distinguir entre sus voces. Es juego. Todo es juego. Intoxicación y locura. Celebración de orificios y protuberancias. La entrada al paraíso. Les dejo que me pinten la cara media vez que no se les ocurra rasurarme el cuerpo. (Arias 2002: 267)

Asistimos en esta escena a una relectura de Las Bacantes de Eurípides, obra clásica del teatro griego que recoge los ritos orgiásticos del culto a Dionisos, dios del vino, de la fiesta y de los bosques. Además, en la obra de Eurípides se evidencia a Dionisos como un maestro del disfraz y de la máscara. Para Nietzche (2000: 251-52), las fiestas en honor a Dionisos (esas idealizaciones de la orgía) están en el origen de la tragedia griega. Y no hay que olvidar que para el filósofo las imágenes de los dioses griegos "nos hablan de una religión de la vida y no del deber, en las cuales está divinizado lo existente, lo mismo si es bueno que si es malo". Es posible ver en la visión nietzcheana del arte dionisíaco un antecedente de la cosmogonía carnavalesca. Más allá de la relación entre los ritos dionisíacos y el carnaval existe un aspecto de la visión nietzchena que ayuda a comprender la utilización de este rito en Sopa de Caracol. Para Nietzche: “[...] en el olvido de sí producido por los estados dionisíacos pereció el individuo, con sus límites y mesuras, [...]". El éxtasis del estado dionisíaco, con su aniquilación de las barreras y límites habituales de la existencia, contiene, mientras dura, un elemento letárgico, en el cual se sumergen todas las vivencias del pasado". (2000: 258-59)

La novela de Arias es el relato de Rodrigo, un exmilitante, de sus peripecias en la organización revolucionaria. Sus tareas, siempre periféricas al campo de batalla, se reducen al trabajo "sucio" de apoyo a la guerrilla. Hoy profesor acomodado en una universidad estadounidense mediocre - gracias a una fotografía (puro simulacro) en traje de guerrillero y a punto de perder el trabajo por un lío con una estudiante- invita a sus posibles aliados a una cena en su casa. Pero tras este motivo aparente se esconde un verdadero viaje a los infiernos de su interioridad, narrado con ironía cínica y brutal y carente de toda complacencia sentimental. 
Sopa de caracol enfrenta al lector con el proceso de despersonalización del protagonista, quien en un monólogo ${ }^{6}$ es, además, el narrador de la historia. En un texto de gran sensualidad, el narrador (como Penteo) persigue su propia ruina, en un estado dionisíaco que le permitirá traspasar sus límites en el olvido de sí, en el cual se sumergen todas las vivencias horribles de su pasado. Todos los elementos del ritual dionisíaco están presentes en la novela en su versión moderna. El vino, los manjares, la danza y la música crean el estado de embriaguez y ánimo exaltado del narrador y de su público, constituido, en la escena final, por mujeres.

En Las Bacantes, Dionisos, por medio de artilugios, convence a Penteo -rey de Tebas- de asistir como observador y disfrazado de mujer, al ritual de las bacantes:

Dionisos- ¡Ah! ¿Quieres contemplar a las bacantes juntas en el monte?

Penteo- Sí, claro, y aún daría por ello una gran carga de oro.

Dionisos- ¿Y por qué tienes tan vehemente deseo de esto?

Penteo- Para verlas agobiadas por el vicio, para desgracia suya.

Dionisos- ¿Y presenciarás de buen grado lo que ha de ser funesto para ti?

Penteo-Tenlo por seguro. Permaneceré silencioso bajo los abetos. (Eurípides 1977: 173)

En la novela de Arias, como en Las Bacantes, el narrador busca su ruina, pero, a diferencia del texto griego, no hay un Dios que mueva los hilos de sus actos. Rodrigo está completamente solo y es, como buen moderno, el único responsable de sus acciones. Ambos textos alcanzan su climax con una orgía y finalizan en el momento post-orgía, o momento de la verdad. En Las Bacantes, cuyo verdadero protagonista es Dionisos, Agave -madre de Penteo- descubre que en su furia ha asesinado a su propio hijo creyendo que se trataba de un león. La orgía en Sopa de caracol propone una modificación notable respecto del texto griego. A pesar de los elementos semejantes, como el hecho de que Rodrigo se disfrace de mujer y sea el blanco de la furia de las mujeres, el rito no termina con su muerte física, sino con la muerte de su identidad sexual:

Al carajo mis pudores. Pudieron más los pedos que los malos olores. Espanto de cara que tengo, por mucho que la pintés no será sino un esforzado palimpsesto, Amapola Ojo Alegre. Voy a quedar linda, eso sí. No lo niego, mis queridos andróginos. [...] La verdad, me sacude la ambigüedad, las mariposas amarillas vuelan dentro de la panza y no alrededor de mi cabeza, porque las estrellas del champán flotan allí, el esplendor de verlas hombres, de ser mujer, la muerte de las identidades sentenciadas, anatematizadas, cortadas, el falo fenece como los fenicópteros fenicios en el farniente, fenómeno de feria, fermento de feligreses férreos cuando no funestos. (Arias 2002: 267-68)

6 Cabe recordar que para Bajtín un monólogo puede ser dialógico (como en el caso de novela de Arias) y un diálogo puede ser monológico. 
Mientras los hombres duermen, las mujeres, con ropas de varón, cambian de nombre: Rosa se convierte en Roso, Amapola en Amapolo y el protagonista se feminiza sin perder del todo sus atributos masculinos, es decir, se convierte en andrógino:

Qué escándalo. El Amapolo Ojo Duro rehace el mundo con su falo artificial. Lo rehace a su imagen y semejanza, sin mí, lo reconstituye en la destrucción de las viejas creencias, las derruidas racionalizaciones que empujaban su lógica hasta barroquizar la cerebralidad, la irracionalidad de la razón. Voy a ser celebrado. Déjenme respirar profundo, acosadores. Contradicciones sin fin. Me excito con Amapolo. Lo admito. (Arias 2002: 267-68)

Rodrigo es el último platillo de la noche, al bailar sobre la mesa vestido de mujer. Pero la transformación subjetiva no se limita a la vestimenta, ya que el personaje, conforme avanza el relato, se feminiza sin llegar a convertirse totalmente en mujer ${ }^{7}$. Su identidad sexual queda sumida en la indefinición, mientras es violado - con un falo inmenso y artificial- por un grupo de mujeres enardecidas, quizá por el relato que acaban de escuchar. En este sentido, Rodrigo es como una Scherazade al revés: si esta cuenta para salvar su vida, el personaje de Arias cuenta para perderse:

El animal que pierde su verdad soy yo. Me voy a morir descuartizado conforme intensificás esta vibración indefinida que resuena más allá de mi muerte. El dolor es exceso, un cuchillo romo tijeretea mis nostalgias, mi virtud, mi sentido de mí mismo, mi respeto, ay, Amapolo, me sacás lágrimas (...) dolor que invita a mi rendición, a entregarme, fundiéndome con el onírico falo del Amapolo Ojo Duro, fundiéndome con los jirones de risas que resuenan en el centro de mi frente como estallidos de granadas, me sumergen en un terror extrahumano ajeno al sentimiento maternal, incomprensiblemente penetrado, inefable, irrealmente poseído, ahh, ahh, rápido, rápido, rapidito, dale, dale, dale, apretame las caderas, sí, no me jalés tanto el pelo, sí, ayy, ayy, me voy a venir, me voy a venir cabrones, ¡me voy a venir! (Arias 2002: 278-79)

La muerte física es sustituida por la violación anal del protagonista, quien goza y sufre simultáneamente hasta alcanzar el orgasmo. Esto hace que la novela de Arias, efectivamente, dé en el clavo (según la visión falocéntrica) en cuanto a la disolución de la identidad sexual del protagonista. Asistimos, así, a una subversión del modelo carnavalesco, que por más transgresor que fuese dejaba siempre a salvo un elemento constitutivo del falocentrismo. Quizá sea importante recordar que, en Roma, uno de los ritos principales del carnaval era la exhibición de un falo erecto que se paseaba en un carro por toda la ciudad. Como ha señalado Bajtín en reiteradas ocasiones, el carnaval estaba asociado a la fertilidad y al

7 Para una interpretación diferente de esta escena ver: Taylor Kane, A. (2009). Ludics as Subversion in Arturo Arias Sopa de Caracol in Bulletin of Spanish Studies, 85: 4, 513-27. 
nacimiento, por lo que la presentación de falos enormes tenía el sentido de reforzar la procreación. Esto muestra, sin negar el poder transformador del carnaval, una faceta católicamente conservadora que no ha sido destacada por la crítica.

El "problema" del hombre penetrado, pasivo y por eso feminizado, tiene una larga historia. En Grecia, el nombre de Katapugon o Kinaidos significaba, entre otras cosas, desvergonzado, obsceno, libertinaje contra natura y, según su etimología, por debajo, por detrás, la nalga, el trasero, aquel cuya ropa dibuja las nalgas. El término cinaedus recoge esta construcción fóbica del hombre desviado sexualmente, que para los romanos era también un terror y que cristaliza, según Quignard (2007: 23) "en la organización psíquica del obsequium, antecedente latino de la culpa cristiana". Según Halperin, "la Antigüedad hacía del kinaidos una amenaza potencial para la identidad masculina de todo hombre y constituía una inversión completa de la jerarquía de género interiorizada, que estructuraba y definía las normas de la masculinidad y que la preservaba contra las múltiples tentaciones del afeminamiento". (Halperin, 2004: 33, traducción propia)

En el siglo XIX, este terror a la pasividad masculina, representada por la penetración anal del hombre, recibía el nombre de sodomía (heredado de la Iglesia Católica) y saturó las páginas de los tratados médico legales de los higienistas y alienistas europeos. Curiosamente, al menos en la lectura bajtiniana del carnaval, un silencio casi total se cierne sobre este tema. Al parecer, el ano habría jugado un papel importante en la cosmogonía carnavalesca únicamente como abertura al mundo, como pasaje de los excrementos. En su lectura de Rabelais, Bajtín dedica unas interesantes páginas al tema de los "limpiaculos". Estos objetos, normalmente asociados con lo alto, (es decir el rostro y la cabeza) como pañuelos y orejeras, son rebajados a cumplir esa sucia tarea. Lo interesante es que, en la interpretación de Bajtín, lo que aparece rebajado, en este caso, es el objeto, nunca el sujeto.

La novela de Arias pone en escena uno de los fantasmas masculinos más acuciantes de la historia de la sexualidad en las sociedades falocéntricas y que, al parecer, ni siquiera la cosmogonía carnavalesca se atrevió a representar. La penetración anal del protagonista -que destruye hasta el último resquicio de su masculinidad y de su machismo- es un espejo en el cual ninguna sociedad falocéntrica ha deseado mirarse. 


\section{Referencias}

Arias, A. (2002). Sopa de Caracol. Guatemala: Alfaguara. . (2010). Arias de don Giovanni. Guatemala: F\&G.

Ávila, M.A. (comp.) (2014). Con mi país bajo el brazo. Compendio crítico sobre la narrativa de Arturo Arias. Guatemala: F\&G.

Bajtin, M. (1998). La cultura popular en la Edad Media y en el Renacimiento. El contexto de François Rabelais, Trad. de Julio Forcat y César Conroy. Madrid: Alianza Editorial.

Eurípides. (1997). “Las Bacantes”. En Teatro Griego, Trad. de Ignacio Errandonea. Barcelona: Editorial Vosgos.

Foucault, M. (1990). Tecnologías del yo, Trad. de Mercedes Allendesalazar. Barcelona: Paidós.

Halperin, D. (2004). Oublier Foucault. Mode d'emploi, Trad. de Isabelle Châtelet, Paris: EPEL.

Kristeva, J. (1997). "Bajtin, la palabra, el diálogo y la novela". En en Criterios, Trad. de Desiderio Navarro. La Habana: Casa de las Américas.

Nietzche, F. (2000). El nacimiento de la tragedia, Trad. de Andrés Sánchez Pascual. Madrid: Alianza Editorial.

Poe, K. (2014). "Arias de don Giovanni. Hacia una poética del cuerpo transexual". En Con mi país bajo el brazo. Compendio crítico sobre la narrativa de Arturo Arias, Ávila, M. A. (comp), Guatemala: F\&G, pp. 149-162.

Quignard, P. (2000). El sexo y el espanto, Trad. de Silvio Mattoni. Córdoba: Cuadernos de Litoral.

Taylor Kane, A. (2009). Ludics as Subversion in Arturo Arias Sopa de Caracol in Bulletin of Spanish Studies, 86: 4, 513-27.

. (2014). "El juego y la ideología en Sopa de caracol". En Con mi país bajo el brazo. Compendio crítico sobre la narrativa de Arturo Arias, Ávila, M. A. (comp), Guatemala: F\&G, pp. 125-146. 